\title{
University-Industry Collaboration: Enhancing Talent Development
}

\author{
Ananda Kumar Palaniappan ${ }^{1 *}$ \\ ${ }^{1}$ Faculty of Social Sciences and Humanities, Tunku Abdul Rahman University College, Kuala Lumpur, Malaysia \\ ${ }^{*}$ Corresponding author. Email: ananda@tarc.edu.my
}

\begin{abstract}
Universities strive to identify and develop students' potential and talent in order to enhance their competitiveness in the job market. Talent development and Industry - University Collaborations are essential in both identifying and developing students' potential to benefit all stakeholders namely, students, universities, companies and the industry as a whole as well as public, professional bodies and government agencies. Student outcome must impact on companies' performance. Hence, objectives should include the narrowing of the Outcome - Impact Gap (OIG) by ensuring students are exposed to the latest technology and skills currently required by the industry. Tunku Abdul Rahman University College, Kuala Lumpur, Malaysia has embarked on many initiatives that have indeed narrowed OIG. It has also achieved Stage 6 of the Stages of Collaborations discussed in this paper for a number of collaborations with companies in the various Industries.
\end{abstract}

Keywords: Industry-university collaboration, talent development, creativity

\section{INTRODUCTION}

In this era of Industry 4.0, there is a critical need to equip students with the right knowledge, skills and attitudes to succeed in the workplace be it as an employee or a selfemployed. Universities are taking many different and innovative approaches to ensure they produce the most marketable students in order to stay competitive and relevant. They strive to enhance students' talents so that they will be competitive in the job market. Another important function universities play is to ensure they contribute to society and continue to innovate through research and commercialization [1].

Among these approaches are efforts to update the curriculum by integrating topics relating to the latest technologies, sending students for internships in related companies, incorporating real world problems in their assignments and students' final year projects. These have been found to be very useful and productive. However, the technological field out there is changing so rapidly that by the time students graduate, the skills they have learnt are already obsolete and companies have to retrain these students thus incurring more expenses. Hence, it is crucial that students are kept up-to-date with the current developments and requirements by engaging with the relevant successful companies to learn the skills that they need to have to not only to survive but also to thrive in this fast-changing world. On the flip-side, it has also been found that companies with university links have higher productivity rates, better market share, enhanced quality of products and services as well as cost competitiveness [2].
Hence, it is a win-win situation in Industry-University Collaborations.

\subsection{Related Work}

There are many types of Industry-University Collaborations that have been implemented and reported in literature. For example, there is the Cambridge-MIT Institute (CMI) which created the Knowledge Integrated Community (KIC) model to leverage the rich research talent of university graduates and the opportunities provided by the industry [3]. In this model, all parties related to research, education and industry are brought together on a common platform called KIC in order to brainstorm innovative approaches and for exchange of knowledge.

Another model uses intermediaries as catalyst to enhance industry-university collaboration [4], [5]. The role of intermediaries is found to facilitate the flow of expertise from the talent pool in universities to the consumers of knowledge in the industry as well as the flow of opportunities from the industry to the students at universities. According to Acworth [3] the key intermediary elements that are of relevance to KIC are i) Scale, ii) Scanning, convening, introductions, iii) Contractual and financial frameworks and iv) Innovation partnerships.

Scale of university system determines the factors that contribute to university commercialization activity. Acworth [3] contends 'the larger and more established the university in terms of experience, staff, finances and research findings, the greater the likely number of spinouts' (p.1234). Other factors include opportunities of venture capital opportunities and commercialization. 
Scanning, convening and introduction refers to the ability of companies to 'search, screen and signal' (p.1234) which relates to enhance Industry - University collaboration.

Contractual and financial frameworks are crucial in ensuring successful Industry-university collaborations. If these frameworks are in place it will facilitate the intermediary to help channel knowledge from universities to companies and opportunities from companies to universities.

Innovation partnerships help build commercially oriented $R \& D$ that enhances the Industry - University collaborations.

Similar approaches have also gain traction among many university-industry collaborations.

\subsubsection{Talent identification and development}

Talent or sometimes referred to as giftedness has been defined in various ways. There are hundreds of talents that are identifiable in individuals. They range from public speaking and mural painting to space craft designing and developing innovative ways for producing sustainable energy sources.

There are also numerous ways of classifying talents and giftedness. One authoritative classification is by The United States Office of Education (USOE). USOE's definition suggests that gifted and talented students are those "who have outstanding abilities, are capable of high performance and who require differentiated educational programs (beyond those normally provided by regular school programs) in order to realize their contribution to self and society" Marland [7]. It has classified giftedness and talent into six categories:

1) general intellectual ability

2) specific academic aptitude

3) creative or productive thinking

4) leadership ability

5) visual and performing arts

6) psychomotor abilities - artistic psychomotor abilities $\&$ athletically gifted.

General Intellectual ability refers to abilities like reasoning, abstract thinking, seeing appropriate relations among things, drawing inferences, understanding words literally \& figuratively, problem-solving and decision making. There are also approaches to measurement of general intellectual abilities - univariate and multivariate. Examples of multivariate measures include Sternberg's Triarchic Theory of Intelligence and Gardner' Theory of Multiple Intelligences. University students' capacity or talents in this area are identifiable in their abilities to secure excellent grades in their chosen field of study. This talent is enhanced by careful designing lectures and activities which make students think critically.

Specific Academic Aptitude is the ability to perform well in their courses. This is easily assessed by looking at the ability of students to excel in all subjects or in specific subjects such as pure sciences or arts.

Abilities in Creative or productive thinking are assessed via various approaches depending the which conceptual paradigm one is focusing on. For example, creativity can be looked as either a Process, Person, Product or Press (or 4 P's for short) [8]. Process refers to the way individuals think to generate new knowledge and think divergently (as opposed to critical thinking). One popular and useful instrument is Torrance Tests of Creative Thinking (TTCT) both the Verbal or the Figural Forms [9].

Creativity has also been assessed using a software that is even more accurate than the paper and pencil tests above. This software, Creativity Assessment System (CAS), Palaniappan [10], employs the Torrance's definition of creativity and operationalizes its measurement by using a computer algorithm that makes it dynamic and more accurate. As more and more respondents attempt the software, the more accurate it becomes as a measure of the on three of the four dimensions of creativity, namely, Originality, Flexibility and Fluency.

Fluency is assessed based on the number of responses or stimulus used in the activity. The CAS software is programmed to read the number of responses attempted. Flexibility is assessed by the number of categories the responses fall into. CAS reads these responses and checks them against a dynamic database initially created based on the manual for The Torrance Tests of Creative Thinking (TTCT) (Figural Form A).

Originality is assessed by the number of statistically infrequent responses given. Frequency is based on a dynamic database that changes after each response is entered into the system by the test taker. The rarest responses get the highest points for originality as shown below:

Responses with frequencies that are:
$<1 \%$
$1-3 \%$
$3-5 \%$
$>5 \%$
are given 3 points
are given 2 points
are given 1 point
no points given

Figure 1 shows a sample activity students are required to attempt to gauge their originality, flexibility and fluency using CAS.

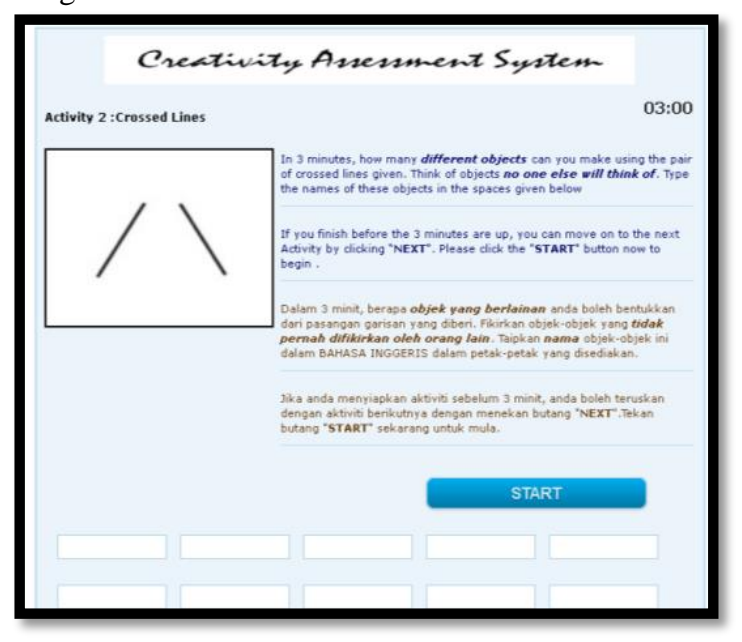

Figure 1 Sample activity respondents will be asked to respond to. 
The person aspect of the assessment of Creative talent refers to the measure of certain defining characteristics of creative individuals gleaned from hundreds of studies of creative individuals. One valid and reliable instrument is the Khatena-Torrance Creative Perception Inventory (KTCPI). KTCPI gives measures of two subscales: What Kind of Person Are You? (WKOPAY) and Something About Myself (SAM). Both subscales take about 25 minutes to complete. The reliabilities and validities of both instruments have been well established by Khatena \& Torrance [11] and Khatena \& Morse [12], [13].

KTCPI comprised two subscales, namely, Something About Myself (SAM) and What Kind Of Person Are You? (WKOPAY). The former has six factors, Environmental Sensitivity (ES), Initiative (IN), Self-strength (SS), Intellectuality (IT), Individuality (IV) and Artistry (AT). The latter has five factors, namely, Acceptance of Authority (AA), Self-confidence (SC), Inquisitiveness (IS), Awareness of Others (AO) and Disciplined Imagination (DI). Creative personality data obtained from the KhatenaTorrance Creative Perception Inventory (KTCPI) and its factor scores were interval data. Hence, university students can be assessed on all these talent potentials validly and reliably.

The next talent ability that need to be enhanced and assessed accurately is Leadership. Methods of identification of Leadership include psychometric approaches, anecdotal data, observation of parents, teachers, peers or case histories. Most universities focus on leadership training from year one to ensure their students are well equipped to face the very competitive world.

Stogdill's leadership Categories [14] is a popular instrument that is used to measure leadership qualities. It measures 6 categories of characteristics associated with leadership, namely, i) Capacity, ii) Achievement, iii) Responsibility, iv) Participation, v) Status, and vi) Situation.

Visual and performing arts is another talent that needs to be focused on especially those who are planning to produce students in the area of Creative Media and Design or Drama. Assessing talent in these areas are usually by trained persons who have been involved in these forms of arts. Hence, there is no one approach that can be used for assessing and enhancing talent in these fields.

Finally, talents in the areas of psychomotor abilities artistic psychomotor abilities as well those who are athletically gifted are quite easy to identify because of their performance can be easily seen and compared.

Institutions of higher learning have some form of talent identification and development programs based on the categories of talent similar to ASOE. This is crucial to develop students' potential and prepare students who are ready to fit into the workplace without any further training. Likewise, in TAR UC, this takes place during classes and as extra-curricular activities and students' talents are developed further through competitions, workshops, company pitching, final year research projects, capstone projects and internships. For final year projects and capstone projects, students' skillsets are matched with industry-related problems. There is also on-going pre- training that enhances students' skill sets. Internships are valuable for exposing students to real-world problems. Exhibitions and Small and Medium Enterprises Week organized by TAR UC also develops students' talent where they are given the opportunity to show-case their ideas.

These areas of giftedness and talent must be identified by professionally qualified persons. In the context of universities, students can be identified by their performance in the various activities organized formally or informally by the universities. Based on the identification, universities are able to collaborate with the relevant authorities to further develop the students' potential.

The accurate identification of student talent is essential in order to provide the necessary enriching environment both within and outside campus so that their talents and potential can be brought to fruition. Hence, it is essential that universities are vigilant and cognizant of the everchanging demands of the industry to provide the right guidance and enrichment activities to produce the outcome (the students) who will go on to create the impact the company expects through this collaboration. This Outcome - Impact Gap (OIG) are narrowed through the various approaches discussed above.

\subsection{Paper Structure}

This paper will discuss as several case studies and instances of the Industry -university collaboration undertaken by Tunku Abdul Rahman University College and several companies in Kuala Lumpur, Malaysia. Via this case studies, several success factors will be discussed. This paper concludes with some recommendations for further improvement based on literature and previous models.

\section{BACKGROUND}

Tunku Abdul Rahman University College was named after the first prime minister of Malaysia. It was established in 1969 as Tunku Abdul Rahman College by Malaysian Chinese Association. It currently has a student population of about 28,000 and has about 150 programmes at both undergraduate and post-graduate levels. It has campuses in Kuala Lumpur (main campus), Penang, Johor, Perak, Pahang and Sabah. It has seven faculties, namely, Faculty of Social Science and Humanities, Faculty of Applied Science, Faculty of Computing and Information Technology, Faculty of Accountancy, Finance and Business, Faculty of Engineering and Technology, Faculty of Built Environment and Faculty of Communication and Creative Industries. It also has a Centre for Pre-university Studies, and Centre for Postgraduate Studies and Research [15]. 


\subsection{Industry - TAR UC collaboration}

Tunku Abdul Rahman University College has always been actively improving both the syllabus and teaching approaches to ensure the students are well qualified and ready for the work assignments in whichever field they have chosen. In line with this, there has been numerous approaches that have been initiated to ensure students turned out by the various faculties are industry relevant. Among the approaches used include organizing road shows, company pitching, competitions, company assignments, final year projects, capstone projects, 2yearsUniversity2 yearsIndusty (or $2 \mathrm{u} 2 \mathrm{i}$ ) initiatives, workshops, internships, Post-graduate study programs and many more.

It has six centres of Talent Development, namely, Centre for ICT Innovations and Creativity (CICTIC), Centre for Computational Intelligence (CCI), Centre for Internet of Things (CIOT), Centre for Data Science and Analytics (CDSA), Centre for Computer Networking and Cyer Security (CCNCS) and Centre for Business Incubation and Entrepreneurial Ventures (CBIEV).

It also has a comprehensive Talent Development Program (Figure 2). Among the various activities organized are company pitching and roadshows which are normally held during the Small and Medium Enterprises (SME) week This is often called the Brand Awareness stage. Next is the Talent Identification stage which occurs during the process of completion of the assignments provided by companies. Following this is the Real-life Project stage where companies provide current and appropriate project titles or problem situations for students to work on as Final Year Projects or as Capstone projects or as $2 \mathrm{u} 2 \mathrm{i}$ program.

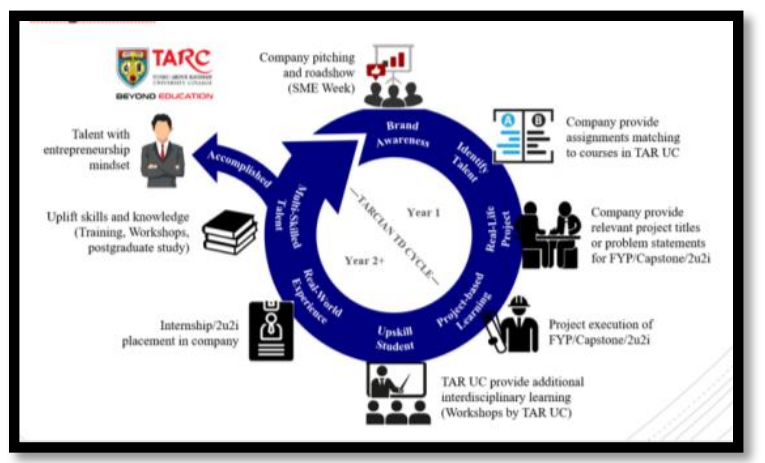

Figure 2 TAR UC industry-academic networked talent development programme by $\mathrm{Ng}$, Lee and Lim [16]

Another initiative is the Project-based learning where students are assigned projects as their Final Year Projects, Capstone or $2 \mathrm{u} 2 \mathrm{i}$ which are aimed at equipping them with the current and marketable skills.

Through additional interdisciplinary learning via workshops students are able to upskill themselves. Another crucial intervention is the Real-world Experiences which students get when they are placed as interns in companies as well as via the $2 \mathrm{u} 2 \mathrm{i}$ programs. Additional Multi-skill talent development are organised to uplift skills and knowledge via training and workshops as well as via postgraduate programs.

It is envisaged that these programs and initiatives will turn out accomplished graduates with the right talents ready for the technological demands and entrepreneurship mindset required by the industries of the future.

\section{CASES OF COLLABORATIONS}

Based on the above model, there are a number of notable cases of collaborations between Industry and TAR UC. Among them are the collaborations with the company Billion Prima to produce X-ray imaging processing, Line scan imaging stitching optical character recognition, and Radiation isotope identifinder PCB and firmware design. Another example of collaboration between TAR UC and industry is the collaboration with the company Ajiya on Material Reservation (C-TRIS), Production \& Material Quality Management System (C-TRIS), E-claim system and E-document depository system (QAQC).

\section{FINDINGS AND DISCUSSIONS}

From the many collaboration between TAR UC and the various companies, it can be said that there are at many different stages. Analysis of these collaborations show that there are essentially six stages of Industry-University collaborations as shown Figure 3:

Stage 1: Discussion of collaboration

Stage 2: Joint activities e.g. Assignments, FYP projects, internships, workshop etc

Stage 3: Signing of MOU and MOA

Stage 4: Implementing collaboration via course restructuring, students assignments, attachments, competitions, etc

Stage 5: Incorporation of students' work in business processes, products, services, etc

Stage 6: Collaboration contributing to a significant measurable impact on the company's performance and bottom line.

Figure 3 Stages of industry-university collaborations by Palaniappan. [17]

Stage 1 refers to the initial intentions to collaboration expressed by either or both the companies and the universities. At this stage there may not be any written agreements signed between the two parties.

Stage 2 is when joint activities are planned between the companies and the universities. Often times, it is the university that initiates these activities. These activities may range from semester assignments to Final Year Projects or Capstone projects. There may also be internships agreements at the end of the program for the students in these companies.

Stage 3 puts both parties in serious intentions to collaborate when they sign an MOU and MOA which details all areas 
of agreement especially those relating to IPs and commercialization.

Stage 4 occurs when companies take the initiatives to ensure there is input from their companies to restructure the course syllabus and the program as a whole which impacts the whole cohort of students.

Stage 5 is when students' work or projects are incorporated into the business processes, products and services. This is an important stage in this collaboration which will eventually lead to the final Stage 6.

Stage 6 indicates to what extent this contribution of the students has eventually contributed to the company's performance and bottom line. This stage can be said to the culmination of a successful Industry-University collaboration. One notable example of such an achievement was the innovative design of the wiper by a TAR UC student though Industry - University collaboration which has substantially contributed to the bottom line of the company.

\section{CONCLUSIONS}

Talent development and Industry - University Collaborations are essential in both identifying and developing students' potential to benefit all stakeholders namely, students, universities, companies and the industry as a whole, public, professional bodies and government agencies. The objectives should include the narrowing of the Outcome - Impact Gap (OIG) mentioned above. Tunku Abdul Rahman University College has embarked on many initiatives that have indeed narrowed OIG. It has also achieved Stage 6 of the Stages of Collaborations discussed above for a number of collaborations with companies in the various Industries. Hence, it is recommended that universities explore the various models of Industryuniversity collaborations and choose one that best suits their discipline and situation and improvise it as the situation warrants since seldom do we find a one size fits all kind of approach in Industry-university collaborations.

\section{REFERENCES}

[1] S. Ankrah and O. Altabbaa, Universities-industry collaboration: A systematic review, Scandinavian Journal of Management, 31, 2015, pp.387 - 408.

[2] C. Malairaja and Zawdie, GScience parks and university-industry collaboration in Malaysia. Technology Analysis and Strategic Management, 20, 2008, pp. 727-739.

[3] E. B. Acworth, University-Industry engagement: The formation of the Knowledge Integration Community (KIC) model at the Cambridge-MIT Institute. Research Policy, 37, 2008, pp. 1241-1254.
[4] J. Howells, Intermediation and the role of intermediaries in innovation. Research Policy, 35, 2006, pp.715-728.

[5] D. Gill, M. R. Minshall, B. Campbell, 2000. Lessons from America. Funding Technology, pp. 2-59.

[6] D. Gill, M. R. Minshall, B. Campbell, 2002. Israel and the virtues of necessity. Funding Technology, pp. 2 69.

[7] S. Marland, Education of the gifted and talented. Report to the Congress of the United States by the U.S. Commission of Education, Washington, D.C: U.S. Government Printing Office.1972.

[8] J. M. Rhodes, An analysis of creativity. Phi Delta Kappan, 42, 1961, pp. 302-310.

[9] E. P. Torrance, Torrance tests of creative thinking: Norms-Technical manual (figural). Bensenville, IL: Scholastic Testing Service. 1990.

[10] A. K. Palaniappan, Web-based creativity assessment system, International Journal of Information and Education Technology, 2012, pp. 255-258.

[11] J. Khatena, J., \& E. P. Torrance, Manual for Khatena-Torrance Creative Perception Inventory. Chicago, Stoelting. 1998.

[12] J. Khatena, J. \& D. T. Morse, Preliminary study of the Khatena-Morse Multitalent Perception Inventory. Perceptual and Motor Skills, 64, 1987, pp.1187-1190.

[13] J. Khatena \& D. T. Morse. Khatena-Morse Multitalent Perception Inventory: Norms-technical Manual. Bensenville, IL: Scholastic Testing Service. 1991.

[14] Stogdill, R. M. Handbook of leadership: A survey of theory and research. New York: Free Press. 1974.

[15] TAR UC Handbook 2020.

[16] S. C. Ng, W.P. Lee, Y. M. Lim. TAR UC Industryacademia networked talent development programme. Tunku Abdul Rahman University College, Kuala Lumpur.

[17] A. K. Palaniappan, A. K. Stages of Industry University Collaboration, 2021, In preparation. 